\title{
La prosperidad hemisférica y el beneficio mutuo: Una visión geopolítica de la naturaleza por parte de la United Fruit Company en la división Golfito 1938-1962
}

The hemispheric prosperity and the mutual benefit: A geopolitical natural world vision from the United Fruit Company Golfito Division 1938-1962

DOI: 10.5935/2237-2717.20160010

\author{
Luis Antonio Conejo Barboza \\ Universidad de Costa Rica \\ elconejoluis@gmail.com \\ Golfito \\ Costa Rica
}

Recibido: 22 de marzo de 2016

Aprobado: 15 de junio de 2016

\section{RESUMEN}

El presente artículo busca caracterizar las representaciones geopolíticas de la naturaleza por parte de la United Fruit Company en la división Golfito durante el periodo 1938-1962. Para alcanzar ese objetivo se utilizaron fuentes como la revista UNIFRUITCO, los reportes para socios así como otras publicaciones de la empresa transnacional dirigidos al público estadounidense como latinoamericano. El estudio enfatiza la representación multimodal que se trabajó para lograr legitimar y expandir la representación de la naturaleza a la mayor cantidad de personas posibles.

\section{Palabras-claves}

Historia ambiental, representaciones sociales, relaciones públicas, United Fruit Company.

\section{ABSTRACT}

This article is looking for typifying the environmental geopolitical representations from The Golfito Division United Fruit Company. Section in the period from 1938 to 1962. Aiming this objective, resources like UNIFRUIT, associates' reports and another periodic publication addressed to the American and Latin American audience were used. The study emphasizes the multimodal that was used to achieve, to legalize and to spread nature representation to the great quantity of possible people.

\section{KEYWORDS}

Environmental history, Social representations, Public relations, United Fruit Company.

\section{Introducción: Geopolítica, propaganda y representaciones de la naturaleza a partir de los Códigos Geopolíticos}

El presente artículo busca caracterizar las representaciones geopolíticas de la naturaleza en la división Golfito por parte de la UFCo, entre los años de 1938 y 1962. En la primera parte de este apartado y a través de ejemplos brindados desde EEUU e Inglaterra se estudiarán los medios y recursos, utilizados para representar la naturaleza por estos países a través de algunas empresas en sus colonias y zonas en donde se instalaron las mismas. La segunda parte se orientará en la explicación de las representaciones geopolíticas de la naturaleza creadas por la UFCo durante este periodo de estudio. Estas representaciones se catalogan como: El conocimiento útil de la naturaleza y El "circulo viviente". La explicación del origen y promoción de estas categorías se desarrollará en función de brindar al lector no solo la explicación del uso de las mismas, sino que también le dará los elementos necesarios para evaluar cómo esas categorías fueron utilizadas para la 
representación de la naturaleza en la división Golfito. Y para finalizar, en la tercera parte se estudiara como esas categorías construidas por la UFCo se utilizaron para representar la naturaleza en la división Golfito.

A partir de las fuentes consultadas, es innegable la cantidad de estudios relacionados con la participación conjunta entre Estados Nacionales y empresas multinacionales de carácter privado, en la construcción, representación y explotación de la naturaleza durante buena parte de los siglos XIX y XX, en donde evidentemente la misma UFCo o la fundación Rockefeller han sido claros ejemplos de esa buena relación y construcción de representaciones. Por otra parte, desde finales del siglo XIX la UFCo ya estaba en Centroamérica y a través de sus reportes para socios, entre otras publicaciones propias de la compañía, desarrollaba percepciones de lo que la región podía llegar a convertirse o representar. Así por ejemplo, a través de los mapas realizados por compañía, se lograba impulsar el objetivo de justificar y construir un "espacio ideal", en donde la relación de poder y capacidad de movilidad entre la región centroamericana, el Caribe y los EEUU a finales del siglo XIX e inicios del siglo XX, marco una pauta en la historia de la representación de la región centroamericana y caribeña. ${ }^{1}$

Trabajos como los de Pratt, ${ }^{2}$ Salvatore, ${ }^{3}$ Jabcos, ${ }^{4}$ Cuvi, ${ }^{5}$ Beinart y Hughes, ${ }^{6}$ entre otros, se convierten en referentes teórico - conceptuales de la historia de esa representación conjunta entre los Estados nacionales y las empresas transnacionales en el continente Americano, África y Asia.

Esta relación se debe entender en el tanto el sistema económico y político predominante de la época (liberalismo) fomentaba una participación más activa de las empresas privadas en algunos aspectos que antiguamente, habían sido competencias del Estado. De igual manera el desarrollo estratégico del proceso expansionista de estas empresas, influyó en la creaciọn, apropiación, legitimación y aceptación de ciertas representaciones de la naturaleza. Por ejemplo, el caso mencionado de la UFCo en algunas ocasiones perpetuó, cambio o modificó ciertas representaciones de la naturaleza construidas desde el estado estadounidense según su contexto histórico y de sus códigos geopolíticos (conjunto de supuestos estratégicos que elabora un gobierno sobre otros estados para orientar su política exterior, están relacionados con imágenes mentales de los esquemas de acción, en síntesis son visiones del mapa parcializadas por un estado en un momento determinado". ${ }^{7}$ Lo anterior, con ayuda también de cambios estructurales en su organización administrativa y de relaciones públicas.

Sin embargo, esa delegación de funciones no se tradujo en una inexistente intervención de los Estados Nacionales. Estos se preocuparon por defender los intereses económicos de sus ciudadanos y empresas, además de participar en procesos de negociación con los países receptores de sus empresas. Aunado a lo anterior, los mismos Estados Nacionales recomendaban a partir de sus códigos geopolíticos y políticas exteriores cuáles lugares eran mejores para la instalación de las empresas, es decir más allá

\footnotetext{
1 James Walter," Cultures of Business, work, and leisure in the United Fruit Company's Caribbean, 1880-1940".

${ }^{2}$ Mary Louis Pratt, Ojos Imperiales.

${ }^{3}$ Salvatore, Culturas Imperiales: experiencia y representación en América, Asia y África y Imperial Mechanics: South America's Hemispheric Integration in the Machine Age.

${ }^{4}$ Jacob. "The World was our Garden: U.S. Plant Introduction, Empire, and Industrial Agriculture,1898-1948".

${ }^{5}$ Nicolas Cuvi. "Ciencia e imperialismo en América Latina: La misión de Chinchona y las estaciones agrícolas cooperativas (1940-1945)" y "Dejen que el diablo haga lo demás": la promoción de productos complementarios en América Latina durante la década de 1940".

${ }^{6}$ Beinart y Hughes. Environment and Empire.

7 Peter Taylor y Flint Colin Geografía Política: Economía-Mundo, Estado-Nación y Localidad. (España, Trama Editorial.2002):99 y de Richard Tucker, Insatiable Apetite: the United States and the ecological degradation of the tropical world.
} 
de una idea de expandir su territorio, lo que buscaban era conocimiento, apropiación de materias primas para sus industrias y un dominio del espacio comercial mundial. ${ }^{8}$

Aquí es importante aclarar que las representaciones geopolíticas, buscan ante todo, estudiar como lo mencionó el geógrafo costarricense Carlos Granados, ${ }^{9}$ la "visiónrepresentación" más allá que del mapa se hace en función de los intereses de las empresas y los códigos geopolíticos de los Estados Nacionales.

Por tal motivo, las representaciones geopolíticas de la naturaleza se entienden en esta visión - representación, no solo al analizar la forma en la cual es dibujado el mapa, sino que también se invita analizar el trasfondo que legitima al mapa y su representación (el código geopolítico), los elementos agregados en el mapa para representar, por ejemplo, productos, personas, etc. Todos esos elementos brindan el conocimiento necesario para visualizar el espacio que se desea visitar, o "representar", en síntesis, además de los mapas en sí, se encuentran otros instrumentos fabricados de igual manera para construir la representación geopolítica de la naturaleza, en donde discursos, fotografías, testimonios, reportes para socios, revistas corporativas, entre otros, toman la batuta de ese tipo de representaciones. Mencionado lo anterior, procedemos a explicar el desarrollo del concepto de naturaleza como un elemento dentro de los códigos geopolíticos.

\subsection{La Naturależa como elemento de los códigos geopolíticos}

La representación de la naturaleza puede variar dependiendo de las transiciones históricas vividas por las sociedades humanas, sin embargo y como se evidenciará en este trabajo, algunas representaciones se mantienen o se transforman muy poco a través de los años.

En varios trabajos, MacKenzie ${ }^{10}$ estudia las representaciones de la naturaleza creadas por el imperio británico. Este autor hace un especial énfasis en afirmar que el imperio británico, no solo debe ser entendido como un imperio de guerra, de explotación o de difusión cultural, sino que también, como un imperio del "viaje". El autor construye esta definición por la cantidad de publicaciones e incentivos dados por el imperio Británico durante buena parte del siglo XIX y los primeros años del siglo XX para que sus ciudadanos viajaran a sus colonias. Por lo tanto, estudiar las postales de viaje, cajetillas de cigarros, películas, entre otros medios dirigidos a la clase media inglesa de mediados del siglo XIX e inicios del siglo XX, se convierte en una manera de visualizar la forma en que el gobierno británico desarrolló y construyó ese imperio del viaje.

Por ejemplo, cuando el autor habla acerca de las guías de viajero, es destacable la manera en cómo se presentaban algunos espacios de las colonias en ultramar para el viajero inglés, la invitación a visitarlas era complementada con una serie de elementos los cuales permitieran al viajante cierta seguridad hacia su destino, por eso, la confección de mapas y fotografías que ilustraran el lugar por visitar eran considerados muy importantes, es más, MacKenzie explica que: "A través del imperio, el mundo podía documentarse, identificarse y detallarse en un índice. Los mapas se consideran, desde luego, como una

\footnotetext{
${ }^{8}$ Eric Hobsbawm, La era del Capital, historia del siglo XX, Industria e Imperio y de Monica Bruckman. Recursos Naturales y la geopolítica de integración sudamericana. (Lima: Instituto Perú mundo; Fondo Editorial J.C.Mariátegui, 2012).

${ }^{9}$ Carlos Granados, "Geopolítica, destino manifiesto y filibusterismo en Centroamérica":2.

10 John MacKenzie, Propaganda and Empire. The Manipulation of British Public Opinion, 1880-1960, ( Manchester y Dover, N. H., Manchester University Press, 1984) del mismo autor, "Imperios del Viaje. Guías de viaje británicas e imperialismo cultural en los siglos XIX y XX", en Culturas imperiales: experiencia y representación en América, Asia y África. Ricardo

Salvatore, comp.(Argentina, estudios culturales,2005).
} 
parte vital de este abarcamiento y exposición del globo: en muchos aspectos, el proyecto imperial era un proyecto cartográfico." ${ }^{11}$

Como se observa, las guías de viaje cumplían otros propósitos además de informar al potencial viajero inglés del siglo XIX e inicios del XX. Estas se convirtieron en herramientas para difundir la representación del código geopolítico Británico, así, la naturaleza, los nativos, su legado arquitectónico, entre otros aspectos, eran ubicados y caracterizados a partir de la visión del escritor de estos materiales del imperio Británico.

Estas guías como se mencionó arriba, se componían de recursos como mapas, fotografías, recomendaciones de los autores, que al fin y al cabo eran la visión representación, que el autor había podido ver y que le interesaba que se publicara. Las mismas iban dirigidas a un público en particular, por lo tanto su distribución se centró en alcanzar a esa clase media inglesa, que fue persuadida a "conocer" y "estudiar" los dominios territoriales alcanzados por su Gobierno. Esto indica que los recursos visuales, escritos y multimodales utilizados, (recursos que utiliza de imagen y el texto de manera conjunta para construir una representación) debían de llamar la atención de este público particular, esos elementos fueron acomodados, distribuidos y representados con una lógica la cual fuera atrayente para el potencial consumidor del viaje.

Un aspecto recurrente es que el resultado original impreso a dichas guías, era un aspecto económico-comercial, el cual era invitar a viajar a las tierras "inhóspitas" y "alejadas" de la "civilización inglesa", además de incentivar relaciones comerciales de intercambio y de poblamiento para los miembros del imperio, pero como se ha visto, con una carga representacional geopolítica bastante fuerte.

La necesidad del viaje se legitimaba primeramente por la búsqueda de aventura, conocimiento y sobre todo vislumbrar algunos espacios y situaciones que desde la óptica europea solo podían suceder en las "zonas salvajes". Esa misma necesidad económicacomercial de "conocimiento", se deriva de una representación de un código geopolítico del imperio británico que nos dice, "que se puede ver en estas zonas y con qué objetivo".

Esa aspiración al "conocimiento" en varias ocasiones estaba cargada con una serie de estereotipos que habían sido construidos desde la lógica europea con respecto a las zonas alejadas del continente europeo, dentro de esta representación se entendía que la mayoría de los "lugares" fuera del continente a excepción de los EEUU, estaban habitados por, salvajes, animales exóticos, etc.

Idea similar nos encontramos en las guías de viaje construidas para el Oeste estadounidense, como las ilustradas por John Gash en donde se puede estudiar como era trabajada la "representación" del "progreso" frente al "salvaje Oeste". Esa representación a través de diferentes recursos semióticos, como el énfasis en poner más claro el avance de los pioneros y más oscuro la huida de los indios y los animales salvajes, mostraba una importante diferencia entre la naturaleza salvaje que se deseaba dominar-conquistar, con las oportunidades que traían los pioneros a los lugares más recónditos de la nación del norte.

El uso de una figura femenina. la cual representaba el progreso por medio de la educación y que bajo sus pies estaban avanzando la línea del telégrafo y la línea férrea, son claras categorías con el fin de crear la representación del progreso que se deseaba llevar hacía el Oeste estadounidense, representado y visualizado como salvaje. Tanto la línea del telégrafo como la línea férrea son dos de los mayores logros de la revolución industrial y capitalista de mediados del siglo XIX, estos se convirtieron en los referentes de la mejoría en

\footnotetext{
${ }^{11}$ Mackenzie," Imperios del Viaje. Guías de viaje británicas e imperialismo cultural en los siglos XIX y XX", 216. el subrayado es nuestro.
} 
los aspectos tales como la comunicación y la disminución del tiempo para recorrer grandes distancias, así, frente a la lejanía del Oeste, estos dos avances no solo facilitaban su conquista, también aproximaban la civilización en un tiempo y distancia bastante rápido y corto.

Aquí, nuevamente las guías hacia el Oeste iban dirigidas a un público en específico que en este caso se le "invitaba" a disfrutar de las nuevas oportunidades brindadas por las tierras incultas e incivilizadas del Oeste estadounidense. Se obviaron las culturas y nativos americanos que vivían esas tierras, su legado, tradiciones y otros factores, en nombre de la búsqueda del "progreso y modernidad".

Este tipo de documentos, así como relatos de viajeros, las novelas ambientadas en las colonias $^{12}$ y las misiones científicas naturalistas, ${ }^{13}$ se convirtieron en instrumentos para construir una serie de representaciones de la naturaleza, ${ }^{14}$ las cuales respondían a las necesidades de los Estados Nacionales y sus empresas interesadas en la explotación de los recursos de esos lugares alejados. ${ }^{15}$

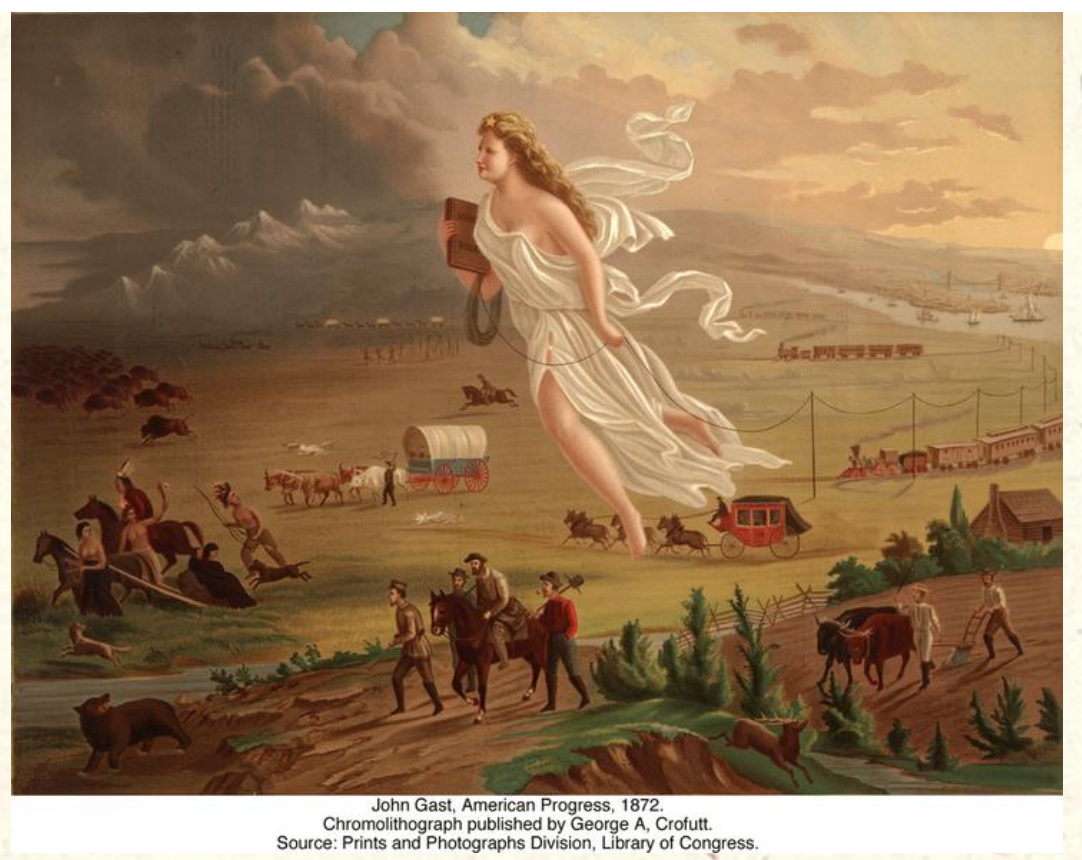

Imagen 1 - "El Progreso Estadounidense," pintura por John Gast, 1872. Fuente: Consultado el 27 de septiembre del 2012. http: http://picturinghistory.gc.cuny.edu/item.php?item_id=180. Todos los derechos de autor pertenecen a sus dueños, se reproduce solo y exclusivamente con fines académicos.

\footnotetext{
12 Rebecca-Anne C. Do Rozario. "Australia's Fairy Tales Illustrated in Print Instances of Indigeneity, Colonization, and Suburbanization". Marvels \& Tales, (25). no.1 (2011): 13-32, Elizabeth B. Fitzpatrick. "The Public Library as Instrument of Colonialism: The Case of the Netherlands East Indies". Libraries \& the Cultural Record, (43), no.3 (2008): 270-285, Clara Claiborne Park, "Artist of Empire: Kipling and Kim", The Hudson Review, (55), no.4 (2003): 537-561, Jorge Marcone. "De retorno a lo natural: La serpiente de oro, la "novela de la selva" y la crítica ecológica". Hispania, (81),no. 2 (1998): 299-308. ${ }^{13}$ Cuvi, "Ciencia e imperialismo en América Latina: La misión de Chinchona y las estaciones agrícolas cooperativas (19401945)" y de Jones. "The World was our Garden: U.S. Plant Introduction, Empire, and Industrial Agri(culture),1898-1948".

${ }^{14}$ Aquí es importante mencionar la tesis de Solórzano en donde el autor hace un especial énfasis en ver estas fuentes no solo como la visión euro centrista o racista, sino que nos invita a explorar más en la visión de los exploradores, cuáles eran sus desafíos y tal vez uno de los aspectos más importantes, las descripciones de los lugares que visitaron. Juan Carlos Solórzano F., "Una crítica a los enfoques "poscolonial” sobre los viajeros europeos y estadounidenses en la Centroamérica del Siglo XIX », Boletín AFEHC N56, publicado el 04 marzo 2013,consultado el 10 de Agosto del 2014. disponible en: http://afehc-historia-centroamericana.org/index.php?action=fi_aff\&id=3449

${ }^{15}$ Pratt, Ojos Imperiales.
} 
La construcción de obras de infraestructura como puentes, vías férreas, "ciudades" y actividades "recreativas" como la caza de animales "salvajes", se convirtieron en elementos que demostraban la superioridad de la modernidad europea versus el salvajismo de las colonias y como el "imperio de la naturaleza" era representado.

Esta relación entre compañías de viaje y los Estados Nacionales, nos podría explicar la razón por la cual la UFCo y los EEUU trabajaron conjuntamente en relación con la "representación de la naturaleza" que se construyó en las divisiones bananeras, pues en su objetivo de consolidar un sistema geopolítico y económico regional, tanto la compañía como el Estado estadounidense, construyeron, legitimaron, adoptaron y perpetuaron unas representaciones de la naturaleza que satisficiera sus intereses geopolíticos y económicoscomerciales. De esta manera algunos espacios se representaban como productores de materias primas y otros como zonas industriales y de servicios.

Visto lo anterior, queda claro la historia de esas representaciones de la naturaleza desarrolladas por los Estados Nacionales y empresas transnacionales. En el siguiente apartado se expone como fue representada la naturaleza latinoamericana desde la visión del gobierno de los EEUU.

\subsubsection{Los códigos geopolíticos estadounidenses y su relación con la naturaleza latinoamericana}

Cuando en 1898 se crea el Seed and Plant Introduction Office (SPI, por sus siglas en ingles), se empieza a consolidar una representación estratégica de la naturaleza latinoamericana dentro de la geopolítica estadounidense, lo anterior por el hecho de que el principal objetivo de esta oficina, fue conseguir el mejor material genético de semillas para catalogarlo y llevarlo a los EEUU en caso de alguna necesidad futura. ${ }^{16}$ Para esa fecha el Destino Manifiesto, instaurado desde 1843 era el código geopolítico dirigido hacia América Latina, por lo que la creación de ese instituto se entiende en la lógica de esa política del Estado estadounidense hacia nuestra región. Aquí, a diferencia de los británicos o de las guías de viaje hacia el Oeste, en vez de promocionar el viaje a América Latina, se buscaba construir un catálogo de las semillas y de productos de consumo para los EEUU identificadas por un grupo de especialistas enviados para dicha misión.

Esta misma oficina, ha inicios del decenio de 1920 se convirtió en asesora de los gobiernos latinoamericanos en especial centroamericanos en términos agropecuarios, dando capacitaciones y sugerencias de cuales productos eran los más indicados para producir en nuestros países. De igual manera, colaboró con compañías como la UFCo dedicada a la explotación de recursos naturales en la región centroamericana. De tal manera, las expediciones y publicaciones de los "investigadores" del SPI terminaban describiendo al final, no solo las plantas y semillas, además por medio de fotografías y textos, la visualización de las plantas, personas y paisajes donde hacían la visita. Evidentemente, el desarrollo de esta "iconografía de la naturaleza", fue gradual y en crecimiento, ajustándose a los nuevos objetos relacionados con el "progreso". 17 Por eso, la visión de mundo a partir de esas representaciones sociales es interpretada más que sentido común, la manera de publicar los mensajes, construir las categorías, entre otros factores, son claros ejemplos que esos documentos del SPI se podían convertir en elementos para legitimar el código geopolítico que se deseaba imponer desde los EEUU.

\footnotetext{
${ }^{16}$ Jones. "The World was our Garden: U.S. Plant Introduction, Empire, and Industrial Agri(culture),1898-1948".

${ }^{17}$ Beinart y Hughes, Environment and Empire, 215
} 
Las imágenes, específicamente ayudaron a "reconocer" el espacio. Ya fuera por fotografías o por pinturas, lo visto se crea para ver, es también la visión del fotógrafo o del pintor o en palabras de Rodríguez, para el caso específico de las republicas bananeras, "[...] estas metáforas alimenticias, productivas substituyen a nivel simbólico naciones por frutas y permiten imaginarlas como tierras baldías, reproducción moderna del viejo tropo colonial, el recurso natural más valioso etiqueta el lugar". ${ }^{18}$

Lo anterior nos brinda una guía para comprender aún mejor la importancia de las representaciones graficas puestas en los mapas, afiches u otros recursos que la compañía banaera necesitara para propagar su ideal del progreso vs naturaleza, esto se entiende también como una propaganda, pues al fin y al cabo, pretende transmitir ideas de una persona o grupo con la intención especifica de influenciar sobre otros grupos de personas. ${ }^{19}$

Así, se crea, construye y legitima la dicotomía de entender la naturaleza como la antítesis del progreso, no es algo fortuito, es un proceso largo que lleva consigo la generación de distintos recursos semióticos, imágenes, discursos escritos y fuentes multimodales. En ese sentido además de las guías, novelas y relatos de viajeros, la construcción de grandes obras de ingeniería como ya se mencionó, legitimaban la presencia de los EEUU en la región latinoamericana y centroamericana en su proyecto de transformación de la naturaleza.

En ese sentido, para el caso latinoamericano es innegable la importancia de la construcción del Canal de Panamá (1904-1914), pues esta tarea, no solo se continuó con la idea de representar a la naturaleza como ineficiente en tanto no fuera penetrada por la civilización, sino que también legitimó la presencia de los EEUU ya no solo en asuntos políticos y económicos, ahora también podían intervenir y disponer de estos recursos naturales a su completa disposición, ${ }^{20}$ entendiéndose a partir del código geopolítico del Panamericanismo. ${ }^{21}$

De igual manera, Salvatore en uno de sus trabajos22 afirma que esta mega construcción, desde el punto de vista estadounidense, fue realizada por intereses geoestratégicos, pero fue representada a nivel latinoamericano, como un símbolo de unidad y cooperación hemisférica. Para este autor, la construcción del canal se vio insertada también en lo que él denomina como las tres utopías del transporte, a saber: La construcción de la carretera interamericana, la construcción de un tren interamericano y la construcción de aeropuertos en los países latinoamericanos.

Lo interesante de estas utopías del transporte, es que si antes la caza de animales se podía considerar como un instrumento para legitimar lo inicuo de la naturaleza, la idea de comunicarnos eficientemente entre el continente y el mundo, se convirtió a finales del siglo XIX e inicios del siglo $X X$, en otro instrumento el cual demostraba la importancia de la penetración de la civilización y lo negativo de la naturaleza sin trabajarla. Aunado a lo anterior y al igual que con el Oeste estadounidense estas utopías del transporte buscaban, simbólicamente, la "unidad hemisférica" a través del aire, la tierra y el agua.

\footnotetext{
18 lleana Rodríguez. Hombres de empresa, saber y poder en Centroamérica: Identidades regionales/Modernidades Periféricas. (Nicaragua IHNCA-UCA. Managua.2011).

${ }^{19}$ Mackenzie, Propaganda and Empire, 3.

${ }^{20}$ Paul Sutter. "El control de los zancudos en Panamá: Los entomólogos y el cambio ambiental durante la construcción del Canal”. Historia Crítica. No.30, (2005): 67-90; Carolina Mora Chinchilla. "El Canal de Panamá: Un Tema Siempre Vigente". Revista Estudios. No. 20 (2007).consultado el 8 de agosto del 2013.

http://revistas.ucr.ac.cr/index.php/estudios/issue/archive

${ }^{21}$ Kellie D Warren." Pan-American Modernism". Tesis doctoral. Universidad de Tulane.2012

${ }_{22}$ Salvatore, Ricardo." Imperial Mechanics: South America's Hemispheric Integration in the Machine Age"
} 
Es más, como lo demuestra Viales, ${ }^{23}$ el síndrome de incomunicación será una de las principales razones por las cuales los Estados Nacionales latinoamericanos, legitimarán el establecimiento de la UFCo en esta región, en el entendido de que la compañía sería capaz de sacar de la incomunicación las regiones más alejadas de los centros políticos de nuestros países y acercarlos a la dinámica internacional del comercio. En ese sentido cuando se instaura la política de la buena vecindad del presidente Rossevelt, la utilización de mapas para ubicar y mostrar a la población estadounidense la ubicación de los buenos vecinos, también legitimaba continuaba con una representación de Latinoamérica como fuente de recursos naturales. ${ }^{24}$

A modo de síntesis, es innegable la relación entre políticas exteriores, códigos geopolíticos e intereses comerciales con la representación desde la dimensión geopolítica de la naturaleza. Los Estados Nacionales son constructores, apropiadores y legitimadores de la representación que se haga de la naturaleza y de la que, desde el punto de vista de ellos, se pueda explotar. Recordemos que la naturaleza dentro de la lógica capitalista desde el siglo XIX, es vista como un bien de consumo, capitalizable, explotable y estratégico. ${ }^{25}$

La representación predominante de la naturaleza en estos casos, nos habla de una dicotomía entre región salvaje y región civilizada. Esta naturaleza de las regiones salvajes, normalmente se encuentra en naciones no europeas las cuales no han alcanzado para nuestra fecha de estudio, el nivel industrial y de comercio que se aspiraba en la época. En esta representación, la única manera establecida y construida desde los países industrializados para alcanzar la "civilización", es por ejemplo, la construcción de mega infraestructuras del nivel de canales interoceánicos como los propuestos para Nicaragua ${ }^{26}$ y Panamá en Centroamérica, la instauración de compañías comerciales o la visualización de estas naciones como espacios de recreo y relajación así como fuentes de materias primas dentro de los códigos geopolíticos de estos países.

\section{Representaciones geopolíticas de la naturaleza por parte de la UFCo, del "conocimiento útil de la naturaleza", al "círculo viviente de los recursos"}

Una de las principales características del llamado imperialismo "informal" estadounidense, se basa en la presencia de algunas compañías surgidas en ese país y su papel en la vida política, social, económica y cultural de los países latinoamericanos, principalmente. La fundación Rockefeller, la Ford y la Good Year sōn algunas compañías que a través de diferentes estudios se ha demostrado que además de dar empleo y utilizar recursos naturales, tenían o se atribuyeron otras tareas más allá de las estrictamente comerciales. Lo anterior evidentemente con ayuda y colaboración de grupos de poder de los países latinoamericanos donde se encontraban. Dentro de esta misma línea, la necesidad imperante de estos grupos latinoamericanos de alcanzar el "progreso" y la "civilización", contribuyó en gran medida a que estas empresas fueran respaldadas desde discursos nacionalistas y progresistas, que explicaban la importancia del establecimiento de estas empresas para la región latinoamericana.

La UFCo, además de banano se dedicó a otros productos como el cacao, el abacá, con el objetivo de suplir las necesidades de los consumidores estadounidenses. Esa misma

\footnotetext{
${ }^{23}$ Viales, Después del enclave.

${ }^{24}$ Amy Spellacy, "Mapping the Metaphor of the Good Neighbor: Geography, Globalism, and Pan Americanism during the 1940s," American Studies, (47), no. 2 (Summer 2006):39-66. Para Spellacy esta política de la buena vecindad se desarrolla en el 1928-1947

${ }^{25}$ Goebel, "Naturaleza Imaginada.

${ }^{26}$ Gobat, Enfrentando el sueño americano: Nicaragua bajo el dominio imperial de Estados Unidos. (Nicaragua, IHNCA-UCA. 2010), 114-115
} 
"necesidad" se creó a partir de diversas estrategias de propaganda que buscaron, ante todo, promover el consumo de esos productos en el mercado estadounidense. La UFCo, fue de las primeras empresas en construir una estrategia que le permitiera legitimar la extracción y modificación de medios biofísicos naturales en América Latina, el trabajo ya citado de Walter, así como los estudios de Soluri, Viales y Montero, dan una visión de lo realizado por la compañía a través de sus estrategias para representar a la naturaleza latinoamericana como algo salvaje y con necesidad de ser trabajado por ellos. A continuación se presentan dos categorías que desde este estudio, explican las representaciones de la naturaleza por parte de la UFCo en el periodo de 1939 - 1962.

\subsection{El conocimiento "útil" de la naturaleza a través de los mapas y textos "informativos": las representaciones geopolíticas de la naturaleza en la división Golfito}

El surgimiento del concepto de "conocimiento útil" tiene sus orígenes en el inicio de la I Guerra Mundial y finales del decenio de 1920 cuando los EEUU decidieron expandir más su comercio hacia América del Sur, así como la política de la buena vecindad, iniciada en la administración Roosevelt (1932-1944).

En dichos periodos, surgen una serie de publicaciones dirigidas hacia exportadores y manufactureros estadounidenses quienes se habían interesado hacia el comercio latinoamericano.

Publicaciones como; "The Young Man's Chances In South and Central America" (1914) de William A. Reid, "The Future of South America" (1917) de Roger. W Babson, entre otras, suministraban "información útil" y práctica, entre otros aspectos a los empresarios estadounidenses para iniciar sus negocios en la región latinoamericana. ${ }^{27}$

Para la UFCo el "conocimiento útil" se entiende desde dos perspectivas en nuestro periodo de estudio. La primera está relacionada con una política la cual desde los inicios de la compañía a finales del siglo XIX fue bastante trabajada. Esta implicaba la ubicación de sus divisiones a través de los mapas en los documentos que publicaba, este aspecto más adelante se vio beneficiado por la política del Buen Vecino del presidente Roosevelt que como se explicó con anterioridad, la idea principal se basa en ubicar en el espacio los buenos vecinos, describirlos y trabajar en la "representación" de estos vecinos a partir del producto agrícola que más se explotaba para los EEUU, de igual manera el acercar la civilización por medio de sus medios de transporte, como la Flota Blanca es una cualidad alcanzada a través del conocimiento de la posición de estos lugares.

Esta lógica de política exterior de la buena vecindad, se entiende por la visión del presidente Roosevelt de crear un ambiente más amigable en su área de influencia, lo anterior, pues debido a las circunstancias de la I Guerra Mundial y la II Guerra Mundial, en donde se dieron cuenta de las limitaciones para importar materias primas desde el Pacífico. Esta situación evidentemente debilitaba en cualquier conflicto mundial las aspiraciones estadounidenses dadas las distancias entre sus proveedores de materias primas y sus enemigos, ${ }^{28}$ fenómeno que también ha sido denominado por otros autores como "guerra económica" ${ }^{29}$

\footnotetext{
${ }^{27}$ Ricardo Salvatore, "Panamericanismo práctico: Acerca de la mecánica de la penetración comercial norteamericana", Culturas Imperiales. comp. Ricardo Salvatore, 271

${ }^{28}$ Esta Justificación se encuentra en varios documentos de la UFCo. Por ejemplo en los reportes para socios entre los años de 1938 y 1942 y el documento: La United Fruit Company y la Región Americana que comprende a Méjico, la América Central y Las Antillas, escrito por A. A. Pollan (vice-Presidente ejecutivo de la United Fruit Company).1944.

${ }^{29}$ Cuvi. "Ciencia e imperialismo en América Latina: La misión de Chinchona y las estaciones agrícolas cooperativas (19401945)", 16
} 
La segunda perspectiva hace referencia al conocimiento de los productos agrícolas, características del suelo, enfermedades entre otros aspectos que son más asociados a la ciencia y la tecnología. En este periodo y como lo han estudiado Chandler, Mazlish y Wilkins, la publicidad y el departamento de relaciones públicas son departamentos que dada su importancia responden a una lógica vertical de repartición de funciones.

Para el año de 1900, los ejecutivos de la UFCo crearon una empresa subsidiaria llamada Fruit Dispatch Company, cuyo objetivo principal en un inicio fue la distribución y promoción del Banano para los mercados en EEUU y Canadá. En 1925 esta misma subsidiaria, distribuía panfletos de cómo manejar los bananos y convocaba en Chicago a una conferencia en donde se hacía expresa la invitación a los directores de las divisiones bananeras del Caribe y Centroamérica. En esta reunión, se vio la necesidad de crear un departamento de publicidad el cual promociona no solo el producto, sino que también propiciara la construcción de mejores lazos entre los trabajadores bananeros de las divisiones y los países de estos, acercar al consumidor al proceso de producción y distribución, además de brindar información general de las características y actividades de la compañía en las divisiones bananeras. ${ }^{30}$

Cuando en 1925 se crea la revista UNIFRUITCO, es con el propósito de incentivar y dar a conocer la información útil de las divisiones bananeras. Desde sus inicios la revista contó con secciones informativas acerca de las divisiones y producción de los diferentes cultivos, así como testimonios de los trabajadores bananeros en las diferentes divisiones. ${ }^{31}$ Otro aspecto interesante es que hasta 1948 la revista UNIFRUITCO será bilingüe, esto podría indicar la importancia que representó para la compañía que los trabajadores de ciertos sectores de las divisiones bananeras en Latinoamérica tuvieran acceso a leer el contenido de dicha revista.

Para el decenio de 1950 y como resultado del incremento del consumo de alimentos procesados, la publicidad será más intensa y se dividirá en diversos medios de comunicación, como la radio, televisión y prensa escrita. De igual manera, aquí se agrega al contexto de la Guerra Fría, pues algunas publicaciones de la compañía traían consigo ideas y conceptos en donde se diferenciaba la explotación de la naturaleza del hemisferio occidental, con la del enemigo comunista. ${ }^{32}$ En ese sentido, es importante también destacar la importancia que significó la incorporación de la "Gran Flota Blanca" (Great White Fleet) a la estrategia publicitaria de la compañía.

La Flota representaba al medio de transporte que llevada la buena nueva de la modernidad y la civilización a cambio de la extracción de "fruits" de la tierra en las divisiones bananeras. Las imágenes en este caso se pueden ver como declaraciones visuales que buscan dejar constancia de un evento importante y que por la naturaleza del material con que se realizó, perpetúa también los ideales bajo los cuales el autor o el editor de esa imagen la seleccionó para ubicarla en ese documento.

Con esa misma idea, cuando se da el nacimiento de la División Golfito (1938) y su posterior ubicación en el mapa hasta 1939, es que la división comienza a ser visibilizada, en

\footnotetext{
${ }^{30}$ Soluri, Banana Cultures, 64

${ }^{31}$ Para un análisis más detallado de la importancia de la Unifruitco, se recomienda: de David Aliano. "Curing the ills of central America: the United Fruit Company's medical department and corporate America's misión to civilize (1900-1940)" EIAL: Estudios Interdisciplinarios de America Latina y el Caribe, (17), no.2, (2006): 35-60 y de Atalia Shragai. "Do Bananas have a culture? United Fruit Company colonies in Central America, 1900-1960, Iberoamericana (11), 42, (2011): 65-84.

32 John H Perkins, Geopolitics and the Green Revolution: Wheat, Genes, and the Cold War. (New York, N.Y.: Oxford University Press, 1997) y de J.R. McNeil y Corinna R. Unger, Environmental Histories of the Cold War, German (Historical Institute and Cambrigde University Press.2012).
} 
este caso concret̃o, para los socios de la compañía a los cuales estaban dirigidos estos reportes.

Los mapas aparecían con regularidad en estos reportes pues ayudaban a ubicar la posición de las divisiones bananeras, así como las rutas de los barcos a los socios. También se brindaba un poco de información. Por ejemplo acerca de las nuevas divisiones de Quepos y Golfito se mencionaba lo siguiente: "Properties and cultivations have been kept in first class condition. To insure a constant supply of fruit large banana developments have been undertaken, with extension of some plantings and commencement of two new divisions on the West Coast of Costa Rica, which are being equipped with adequate rail and port facilities." 33

Como lo evidencia la cita, para el año de 1939 el crecimiento de la producción necesitaba la creación de dos nuevas divisiones, aspecto analizado con anterioridad por la UFCo al menos para el caso costarricense y que hasta esa fecha se consiguió la construcción y consolidación de esas divisiones bien equipadas con adecuadas facilidades para trenes y barcos. ${ }^{34}$ De igual manera, el uso de un recurso multimodal en donde el mapa con la ubicación de Golfito y la cita donde se mencionaba la creación de las nuevas divisiones bananeras en Costa Rica son un ejemplo de cómo la UFCo trabaja la difusión de la información y por lo tanto de las representaciones de la naturaleza que le interesaban.

Aquí el "conocimiento útil" de la naturaleza se centra en dar la ubicación y una explicación a las acciones realizadas por la compañía, de igual manera la presencia del mapa es un elemento que sirve para apreciar cómo, poco a poco, se han ido integrando más nombres de lugares de países donde están ubicadas las divisiones bananeras. El mapa como una imagen científica, es un tipo de discurso el cual legitima en gran medida la representación de la naturaleza.

Al seguir con la idea, el texto ayuda a contextualizar el mapa, y ese ejerció es desde nuestro punto de vista fundamental en el tanto de que permite al lector del reporte analizar y ver con más claridad y detalle la importancia de ese nuevo topónimo el cual se encuentra en el mapa. Es así como surge la representación de la división Golfito en la historia de la UFCo, a partir de su posicionamiento en un mapa, herramienta importante dentro del contexto geopolítico de la época.

El mapa existe para ubicar, imaginar y pensar en este caso concreto en la distancia a la cual se encuentran las divisiones bananeras con respecto al país madre de la empresa. Estos aportes del mapa se concibieron para ayudar a interpretar de una manera más adecuada las necesidades de inversión que debía de realizar la compañía, al menos para los socios, esto era algo importante de aclarar, pero les permitía visualizar el alcance de la inversión más allá de los términos económico-comerciales, es hasta cierto punto una percepción de control hacia lugares distantes de su país y de ayuda a construir mejores lugares en términos de explotación de recursos y calidad de vida.

La manera en la cual los recursos visuales y escritos se complementan para visualizar la dinámica presente en los reportes para socios se entienden en la manera en como brindaban en un pequeño espacio y una cantidad corta de páginas, un resumen bastante aceptable de lo que sucedía en las divisiones bananeras. Los reportes son una fuente importante para determinar cuál era la representación de la naturaleza que se construía a un nivel más alto de la administración. De igual manera, si leemos la revista UNIFRUITCO por ejemplo, nos toparemos con cierta similitud en el tipo de discurso escrito y visual, esto

\footnotetext{
${ }^{33}$ Fortieth Annual Report to the Stockholders of the United Fruit Company, For Fiscal Year 1939, 5. el subrayado es nuestro

${ }^{34}$ Jones y Morrison, "Evolution of the Banana Industry of Costa Rica".
} 
demuestra la gran coherencia de representaciones mostradas por la UFCo, aspecto que evidentemente muestra una capacidad organizativa bastante eficiente. En ese sentido, es importante dejar constancia que la importancia estratégica de la región centroamericana se empezó a construir antes de la llegada de la UFCo o de los conflictos armados los cuales potenciaron la visión de surtidor de materias primas a la región centroamericana.

Esa visión de ver a la "Middle America" como canasta de recursos en términos de Gudynas implicaba también verla desde distintos modos de explotación y transformación, así como algunas ideas conservacionistas. ${ }^{35}$ La novedad hasta cierto punto fue el agregado a partir del establecimiento de la UFCo como la compañía especialista en el cultivo de productos necesarios para satisfacer las necesidades bélicas estadounidenses.

Por último, la presencia de la UFCo en nuestra región no debía de ser entendida como una expansión del poder estadounidense, se debía ver como una ayuda y un beneficio mutuo aspectos que difícilmente muchos latinoamericanos compartieron. Esta funcionalidad de los reportes para brindar "conocimiento útil" a los socios, se convirtió en una tendencia bastante importante en las publicaciones dirigidas hacia un público más amplio, en donde la revista UNIFRUITCO jugó un papel fundamental. Así por ejemplo en el año de 1949 es cuando encontramos a Golfito en un reportaje de la UNIFRUITCO como lo muestra la imagen 2. Este material como se mencionó con anterioridad era distribuido ien todas las divisiones bananeras y curiosamente a partir de 1948 lo hacía de manera bilingüe, en inglés y castellano. ${ }^{36}$

Rica en imágenes, testimonios, fotografías y de buen material, la revista permitía en sus diversas partes vislumbrar lo que se hacía en las divisiones bananeras y subsidiarias tanto en Latinoamérica como en los EEUU. Por eso, la aparición de las divisiones en reportajes marcaba una pauta en donde se deseaba mostrar a los trabajadores los avances de la compañía en la región. Para este caso en concreto es interesante analizar el ordenamiento de la imagen con respecto a la tipografía. La imagen se encuentra en la parte superior y abajo aparece el texto, esto le dicta al lector cómo interpretar la información de la fuente multimodal. Así, primeramente estudiar la imagen, para después concentrarse en el texto. Esto es interpretado al tomar en cuenta el mecanismo desarrollado desde el análisis crítico de discurso desde la gramática visual.

La imagen permite conocer la historia de lo que tuvo que suceder en Golfito para que se construyera la ciudad bananera. Se representa la ayuda que puede generar una empresa de los EEUU en un país latinoamericano. Así la división Golfito, con su montaña a espaladas de la ciudad bananera, posee un puerto, aeropuerto, casas, en síntesis, una ciudad ordenada en contraposición al desorden la selva. Esto posiciona a la división Golfito y su naturaleza como un ejemplo exitoso de lo que se puede hacer.

Según la tipografía mostrada abajo, el tamaño de la letra, la cantidad de palabras y el orden de las palabras, refiere al orden con que debe de ser leído el texto y la importancia de las diferentes representaciones.

El nombre de Golfito aparece con la letra más grande, por lo tanto es el elemento a tomar en consideración, es la referencia de lo que se está viendo y de lo que se desea hablar. Después de generar una reacción por la imagen, lo siguiente que llama la atención es este topónimo, que ya es conocido por los potenciales lectores, recordemos que desde

\footnotetext{
${ }^{35}$ Eduardo Gudynas, "Imágenes, ideas y conceptos sobre la naturaleza": 272-273

${ }^{36}$ Shragai, "Do Bananas Have a Culture".
} 
hacía diez años el nombre de la división Golfito aparece en los documentos de la UFCo. ${ }^{37}$ De igual manera, si existiera alguna duda de la ubicación de Golfito, la colocación de un mapa de Costa Rica en la esquina inferior izquierda y con un color distinto al resto de los colores utilizados en la fuente, nos invita a verlo y analizarlo. Seguidamente, la frase que parece... "Es el centro de uno de los baluartes de la UFCo", no deja duda de la representación que se deseaba dejar clara acerca de la división Golfito. Esa frase para Golfito, nuevamente legitima la representación de este baluarte dentro de las aspiraciones de la UFCo en lo que respecta a la conquista de la naturaleza.

La imagen, el texto, así como la manera en la cual fueron ordenados en ese reportaje nos muestran un trabajo muy bien desarrollado para construir y perpetuar una representación de la naturaleza donde es transformada gracias a la buena voluntad de una empresa estadounidense y a nivel geopolítico, posiciona el nombre de la división bananera como un modelo exitoso, por consiguiente, un modelo a seguir.

\footnotetext{
${ }^{37}$ Para ampliar un poco más en la importancia de las tipografías y en las imágenes se recomienda: Sandra lleana Cadena Flores y Hortensia Mínguez García. "De la tipografía en el libro al libro-arte tipográfico. From the typography in the book to the typography book Art." El artista: revista de investigaciones en música y artes plásticas, no. 9 (2012): 101-124.
} 


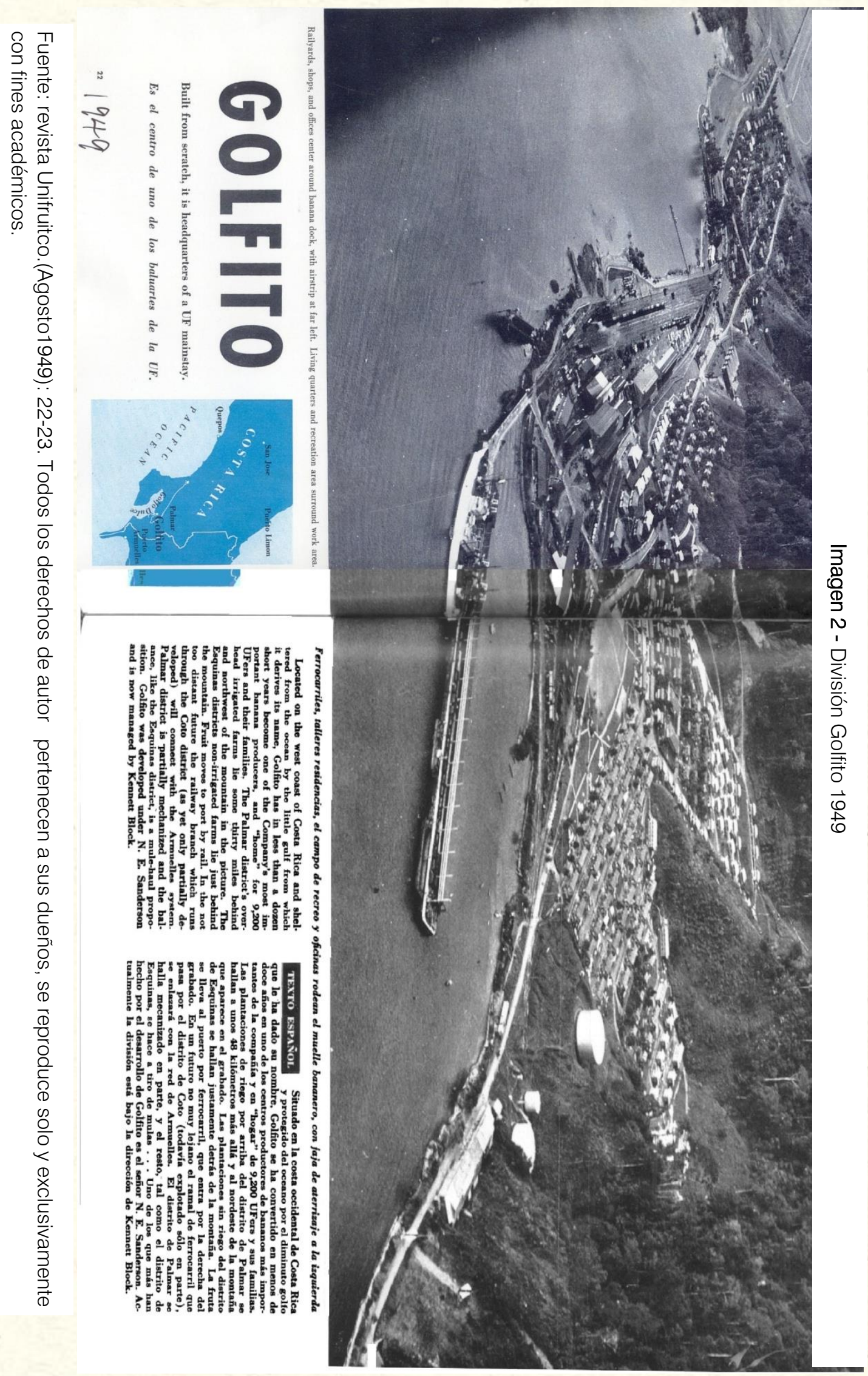

Lo anterior también se corrobora en el tanto a partir de la lectura de la oración que aparece justo debajo de la imagen, "Railyards, shops, and offies center around banana dock, with airstrip at far left. Living quarters and recreation area surround work area." queda constante la representación de una ciudad modelo en las faldas de la selva. Esta imagen estaba impresa en dos páginas, se daba la continuidad al resto de la fotografía de Golfito y 
se detalla con una tipografía más pequeña otros detalles de esta división. Así, aspectos como su importancia nacional y la continuidad de trabajar para seguir "civilizando" el territorio se hacen patentes en este reportaje.

El orden para apreciar la noticia se hace en base a nuestra manera de leer, de izquierda a derecha, por eso la cantidad, tamaño y posición de la fotografía lleva la mayor cantidad de elementos determinantes en toda la noticia. ${ }^{38}$ Este ejemplo nos ayuda a entender la representación de la naturaleza en la división Golfito, primeramente se visualiza lo que la compañía puede hacer en terrenos adversos y selváticos, se brinda la ubicación de ese espacio transformado y se contextualiza la imagen con texto ordenado y puesto con un claro objetivo de priorizar representaciones a partir del tamaño de la tipografía. Expuesto lo anterior y continuando con las representaciones que surgen a partir del "conocimiento útil" de la política del buen vecino y sus repercusiones en algunas acciones de la UFCo, nos interesa analizar una subsidiaria creada con el objetivo específico de conocer a los buenos vecinos de Centroamérica y del Caribe.

\subsubsection{EL Middle American Information Bureau (MAIB): La naturaleza centroamericana y caribeña en las divisiones bananeras vista como un elemento estratégico dentro de la lógica de la UFCo}

Para el âño de 1943 la UFCo creó una subsidiaria llamada Middle American Information Bureau (MAIB), cuyo principal objetivo era distribuir información acerca de de lo que ellos denominaban como Middle America, ${ }^{39}$ a expertos en asuntos inter-americanos y al público estadounidense en general. ${ }^{40}$ Esta subsidiaria fue creada con la importante colaboración de Edward Bernays y Charles Morrow Wilson considerados como los padres de las relaciones públicas y de sus mejores exponentes durante buena parte del decenio de 1940 y 1950. Así por ejemplo, cuando en 1951 se publicó "Place Names in Middle America" en cuyas primeras paginas se mencionaba "... conduted by United Fruit Company in the interest of public understanding of eleven republics of Middle America and their importance to the United States". Lo brindado en este texto era una pequeña descripición de los países y algunos lugares, sobre todo aquellos con presencia de divisiones o propiedades de la UFCO. Por ejemplo de Costa Rica o (Kosé - tah rré - kah) como era escrita la fonología del término, se mencionaban las provincias, algunas fincas como "El Cacao" y de Golfito se mencionaba lo siguiente: "The two banana ports of Golfito and Quepos, on the west coast, have been playing increasingly important roles in the export trade of recent years, due to the fact that the United Fruit Company has shifted most in banana production from Atlantic to the Pacific lowlands." 41

En esta cita, queda claro la importancia estrategica que iban tomando para la UFCo las divisiones de Golfito y Quepos, así como queda un ejemplo del tipo de material que desde esta subsidiaria salía en donde era importante mostrar la importancia de esta región para los EEUU. El objetivo fundamental de esta subsidiaria desde el punto de vista del "conocimiento útil de la naturaleza", se enfatizó en la creación de documentos multimodales los cuales brindaran información concisa y rapida acerca de las propiedades de la UFCo en

\footnotetext{
${ }^{38}$ Rudolf Arnheim, El pensamiento Visual (España, Editorial paidos.1986).

${ }^{39}$ Para ampliar acerca de este concepto ver, Carolyn Hall and Héctor Pérez Brignoli, Historical Atlas of Central America, (EEUU: Oklahoma Press,2003), 4-5

${ }^{40}$ United Fruit Company. Forty-Ninth Annual report to The Stockholders of the United Fruit Company. For the Year 1948.26;

Myers." The United Fruit Company in Central America: Histrory of a public relations Failure":253-254 McCann, Una Empresa Norteamericana, 42-43, en Maria José Canelo. "Good Dances Make Good Neighbors: The U.S. Welocome Carmen

Miranda". Centro de Estudios Sociais e Faculdade de Letras da Universidad de Coimbra.

${ }^{41}$ Middle American Bureau. Place Names in Middle America. (New York.1951), 35.
} 
la región de estudio. Estos materiales podían servir de complemento a las representaciones que en otros medios de difusión de la compañía como las películas, la UNIFRUITCO y los reportes para socios, aparecían.

La creación de este departemento se inscribe en la importancia dada por la UFCo a distribuir la información necesaria al público estadounidense con respeto a su área de influencia. De igual manera, el interés de crear documentos que brindaran información útil acerca de los países en donde estaban las divisiones bananeras, se explica en el tanto la política de la buena vencidad propiciaba este tipo de documentos, que en teoria, beneficiaban a ambas partes, al público estadounidense y a las regiones de las plantaciones bananeras.

El MAIB fue considerado como un departamento de propaganda que aunque desaparecio a inicios del decenio de 1950, se convirtió en la base de lo que el nuevo departamento de relaciones públicas de la UFCo debería de hacer, brindar la "información" adecuada, a un público selecto.

\subsection{El círculo viviente de la naturaleza: El departamento de relaciones púbicas de la UFCo trabaja con la geopolítica y recursos naturales en la división Golfito 1952-1962}

A inicios del decenio de 1950 el departamento de relaciones públicas de la UFCo sufrió una serie de modificaciones respondiendo a las necesidades de la época. Por ejemplo para 1952 y con el interés de estar más cerca con las realidades cotidianas de las divisiones bananeras, se instauró en San José la división latinoamericana del departamento de relaciones públicas. ${ }^{42}$

En 1955 la UFCo reorganizo ese departamento de relaciones públicas como un elemento aparte de las vicepresidencias, en donde ahora respondía más directamente a la presidencia de la compañía. La primera tarea dentro de esta reorganización fue trabajar en un proyecto nombrado "el circulo viviente" (This Living circle strengthens the Americas). ${ }^{43}$

Esta campaña a diferencia de las estudiadas anteriormente, se dirigió en gran medida para el público latinoamericano, sin embargo, publicaciones de esta campaña también aparecieron en medios escritos estadounidenses. Por ejemplo, esta propaganda la encontramos en la revista Life $^{44}$ tanto en inglés como la edición en español, en periódicos de habla inglesa, periódicos especialistas en publicidad como el Analysts Journal, el semanario financiero Barron's National Bussiness and Financial Weekly y el New York Herald Tribune. ${ }^{45}$

La importancia de las relaciones públicas radica en que a diferencia de la publicidad, que solo le interesa vender un producto, las relaciones públicas de las empresas trabajan por crear una imagen de empresa que muestre sus virtudes y logros para la sociedad.

De hecho, en el decenio de 1950 la sociedad estadounidense vivía un periodo de relativa prosperidad y estabilidad, aunado a lo anterior los medios y estudios de publicidad tuvieron su apogeo con el surgimiento de nuevos materiales, nuevas tendencias, y una mayor cantidad de medios para distribuir su "información." También a esta época se le conoce por ser la era de la consolidación de la identidad corporativa, en otras palabras, es el periodo en que la marca de una empresa se convirtió en el máximo exponente de la empresa.

\footnotetext{
42 Stacy May, Galo Plaza, La empresa Estadounidense en el extranjero. Caso de estudio: La United Fruit Company, (National Planning Association, 1958), 228.

${ }^{43}$ De esta manera es citado en las fuentes en ingles.

${ }^{44}$ Solo en la revista Life en español se encontraron anuncios en español.

${ }^{45}$ Soluri, "Landscape and Livelihood", 3.
} 
De igual manera y debido al contexto las empresas estadounidenses en este periodo se centraran más en el estilo de prácticas gerenciales las cuales buscaban la promoción de valores y estilos de vida en este caso estadounidenses. ${ }^{46}$

Estudiando el contexto regional y mundial surgen diversos temas y agendas insertadas en la cantidad y calidad de información de estos departamentos. Por ejemplo, el inicio de la Guerra Fría, con sus aspectos ideológicos que surgieron en todos los niveles de la sociedad, dio pie a que este departamento trabajara no solo en mejorar la imagen de la UFCo, sino también la del sistema económico-político de este lado del globo. Así, cuando en 1954 se da el derrocamiento del presidente Arbenz en Guatemala los EEUU dejaron bastante claro que ellos defenderían los intereses de sus empresas frente a cualquier arrebato considerado comunista en la región centroamericana. ${ }^{47}$

De igual manera la compañía además de criticar la política agraria del presidente Arbenz, también tuvo su participación en la guerra ideológica contra los comunistas. La realización de la películas como "Why the Kremlin Hates Bananas", en donde se establecía la divergencia entre sistemas políticos-económicos, a partir de analizar los pros y contras del establecimiento de la compañía en la región centroamericana, fueron algunos de los mecanismos que utilizó la compañía por su parte para detener el avance de los "elementos comunistas".

Esta cinta fue destruida por la misma compañía años después, tenía una duración de 13 min y fue producida por Edmund S. Whitman, director del departamento de relaciones públicas de la UFCo desde 1953 y esposo de la secretaria personal del presidente Eisenhower. Además de la película, Whitman escribió en 1955 el texto: How an American company, through advertising and public relations, has combatted communism in Latin America, ${ }^{48}$ ambos documentos con una muy cargada lucha ideológica contra el comunismo.

Sin embargo, en otras ocasiones y a través de sus medios de comunicación, la compañía en su discurso buscaba la conciliación, así en el reporte para socios de 1953 ese deseo se hizo palpable como la colaboración del Departamento de Estado estadounidense: "The Company has filed with the departament of State, for preservation to the government of Guatemala, a claim for just compensation for the expropriation including the appraised present value of the lands and improvements expropiated, and the damage caused to the Company by depriving it of its reserve banana lands and greatly shortening the useful life of extensive facilities on the west coast." 49

Aquí, la Compañía solicitaba respetar las decisiones y procesos del gobierno guatemalteco, situación mostrada por muchos de los empleados de la compañía que no estaban de acuerdo en la forma en que se estaba combatiendo el comunismo. ${ }^{50}$ Lo único solicitado para este caso era una compensación, sin embargo la idea de un gobierno con políticas consideradas como comunistas para esa fecha en Centroamérica fue vista como muy peligrosa, es más desde 1948 con la conferencia de Bogotá, EEUU llamaba la atención acerca de los peligros de las inserciones comunistas en la región latinoamericana.

El departamento de relaciones públicas en este tipo de acontecimientos jugó un papel importante en el tanto de que trato de transmitir la idea que la compañía para el caso

\footnotetext{
${ }^{46}$ Chandler y Mazlish, Leviathans: Multinational Corporations and the New Global History, 91

${ }^{47}$ Margarita López- Maya. "The chance in the discourse of US-Latin American Relations from the End of the Second World

War to the Beginning of the Cold War ". Review of International Political Economy, (2).no.1, (Invierno, 1995):135-149.

${ }^{48}$ United Fruit Company,1955, este autor escribió también, Porque la interdependencia es importante para las Américas, El circulo Viviente (1956).

${ }^{49}$ Annual Report, United Fruit Company.1953..4

${ }^{50}$ McCannan. Una empresa norteamericana. La tragedia de la United Fruit.
} 
guatemalteco había sido una víctima, y no el victimario, este aspecto que se puede discutir a mayor profundidad, pero no es el caso para esta investigación: Por otra parte, parece pertinente mencionar pues dentro de esa guerra ideológica, la transformación de la naturaleza desempeño un rol importante en esa guerra ideológica.

De igual manera, la relación del Departamento de Estado y la UFCo fue una relación muy estrecha. Son conocidas las visitas de los embajadores y representantes de las embajadas estadounidenses a las divisiones bananeras, en donde los temas de conversación iban desde asuntos triviales, hasta asuntos geoestratégicos. Por ejemplo, cuando el embajador Woodward visitó la división Golfito, escribió al Asistente del Secretario de Estado de la Oficina de Asuntos Interamericanos Henry Holland lo siguiente:

\begin{abstract}
You know the great importance of this to United States relations as a whole in the banana-producing countries and in the rest of Latin America, but I believe that few people in the United States realize the extent to which the Company and its reputation is symbolic of the United States to thousands and thousands of people in Latin America. The reason I am writing to you is that it seems to me that such a good foundation has now been laid by the Company that, by the concerted exertion of the ingenuity that must be possessed by the splendid brains in the Company, the Company could at comparatively little additional expense gain Hemisphere-wide reputation for being "out in front" in constructive labor and public relations rather than always appearing to be fighting a "rear guard action" and getting a bad press in return for the really formidable concessions it has made: You may be able to encourage thinking in this vein in your conversations with Company officials. Certainly there is no effort that could contribute more to the reputation of the United States in Latin America, and particularly in the Caribbean area. ${ }^{51}$
\end{abstract}

Esta declaración nos permite visualizar la importancia de la UFCo como un agente de la buena voluntad del gobierno estadounidense. La solicitud de hacer constatar a las autoridades de la compañía su papel primordial en la tarea de perpetuar las buenas relaciones con los países latinoamericanos, indica la importancia que debían de tener las relaciones públicas de la compañía. Un problema con la compañía sería un asunto de Estado, por decirlo de alguna forma para el gobierno estadounidense. ${ }^{52}$ En ese sentido, la división Golfito y lo que pasara ahí era en gran medida un catalizador de la percepción del pueblo de Golfito y de Costa Rica hacia el gobierno de los EEUU. La división se convertía en un agente de la geopolítica estadounidense, en el tanto representaba el éxito o el fracaso de esa geopolítica. La cita anterior nos muestra la importancia de este departamento en el contexto regional en el cual se encontraba Centroamérica y la UFCo. La tarea de mejorar la imagen de la empresa después de lo ocurrido en Guatemala, así como asimilar e interpretar los movimientos sociales de los trabajadores bananeros, sería una tarea bastante dura, pero al igual que con la creación de un mercado para el consumo del banano, la compañía trabajo arduamente para conseguir un balance positivo a su favor.

La imagen 3 muestra la imagen de la campaña del círculo viviente. La estructura gráfica es colocada en la parte superior. Este punto nos indica la importancia que tenía la transmisión de las representaciones por medio de las imágenes, estas permitían una mejor y

\footnotetext{
${ }^{51}$ Foreign Relations of The United States, 1955-1957, Volume VII, American Republics: Central and South America, Document 3: Letter From the Ambassador in Costa Rica (Woodward) to the Assistant Secretary of State for Inter-American Affairs (Holland) San José, October 27, 1955. el subrayado es nuestro.consultado el 4 de febrero del 2013. http://history.state.gov/historicaldocuments/frus1955-57v07/d3.

52 Para ampliar acerca de la importancia de los documentos del Departamento de Estado en Costa Rica se recomienda: Jacobo Schifter Sikora, Las Alianzas conflictivas (San José Costa Rica, 1986).
} 
mayor compresión del público en el tanto de que la mayoría de elementos gráficos presentes eran fácilmente asociados a varias percepciones de la naturaleza y del desarrollo aceptadas para la época. ${ }^{53}$

El primer elemento gráfico que llama la atención; es el mapa de una parte del contiene americano, este nos indica la posición y ubicación geográfica de la idea del círculo viviente, es en esa parte del globo donde la transformación de la naturaleza impulsada por una empresa transnacional está dando lugar a una serie de mejoras y ejemplos a seguir. Su ubicación en el centro de la imagen permite también visualizar elementos en común con el código político de la buena vecindad, así como reflejar que la incidencia desde otros continentes no es necesaria, aspecto asociado con el conflicto ideológico de la época, elemento que más adelante se tratará.

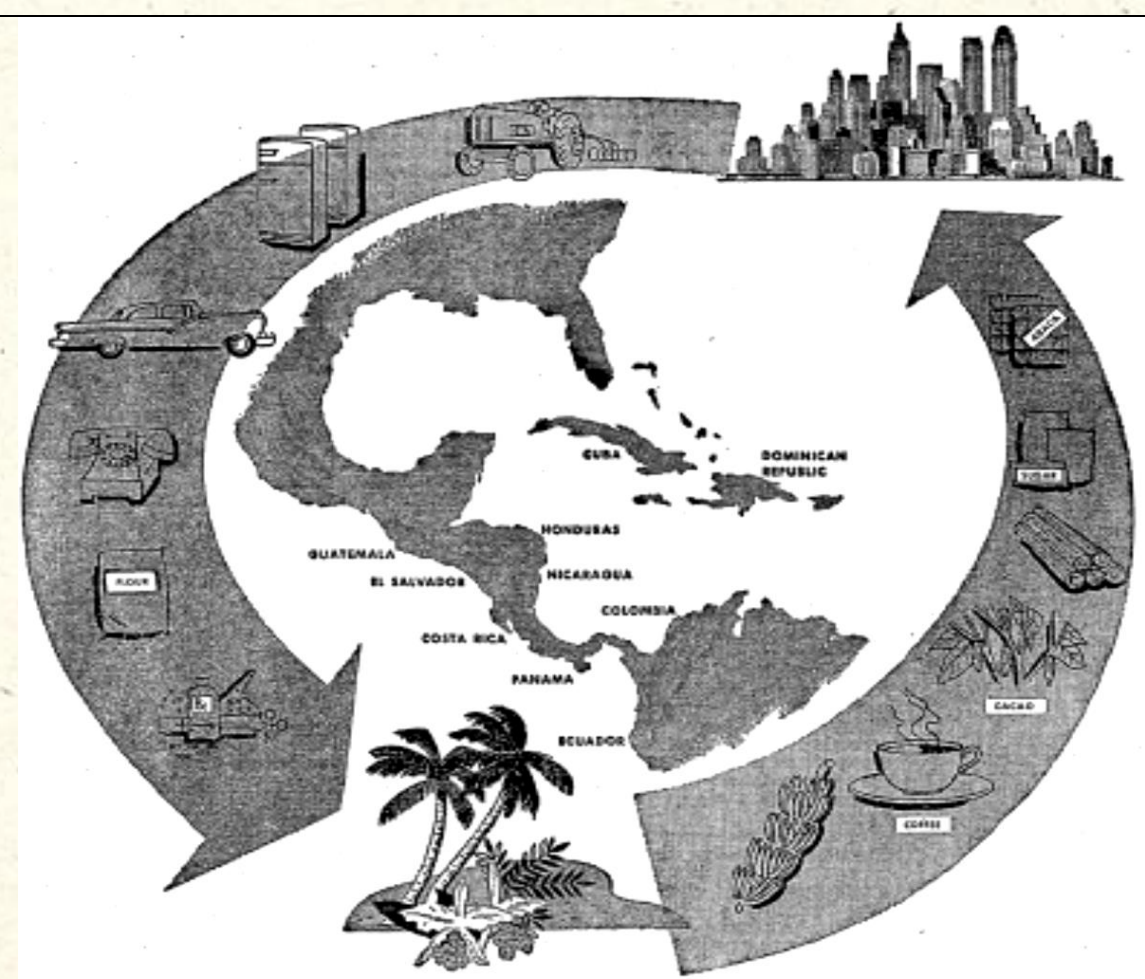

THIS LIVING CIRCLE STRENGTHENS THE AMERICAS

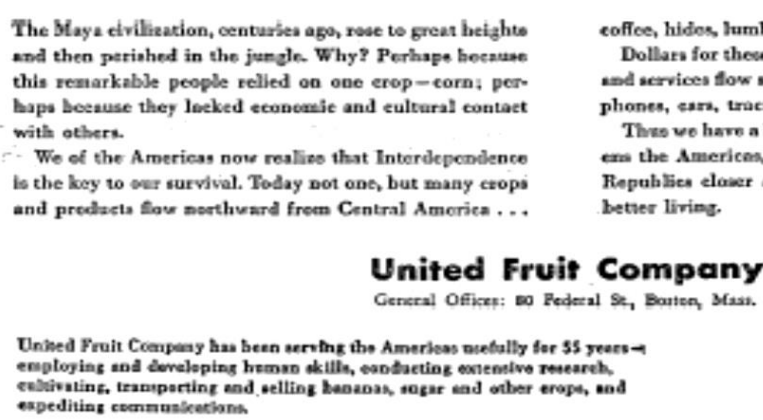

eofice, hidios, lumber, bannasn, escao, shaca ... for thewe erops and for Ceatral Amerins's goods Thes ve have a living circle of econsonio that strengthan the Americes bringing the poople of the Americas Republies elower aed eloser in bonds of fricedehip and betier living.

Imagen 3 - This Living Circle Strengthens the Americas.

Fuente: Base de datos Jstor. Barron's National Business and Finantial Weekly. (Enero 16,1956):20. Consultado el 4 de febrero del 2013. Todos los derechos de autor pertenecen a sus dueños, se reproduce solo y exclusivamente con fines académicos.

\footnotetext{
53David Dabner, Diseño, maquetación y composición: compresión y aplicación, (España, Blume.2005), 26-27.
} 
Seguidamente la imagen de la ciudad (representación de la civilización)54colocada en la esquina superior derecha, contrapuesta con la representación de lo que podría ser la idea de una selva modificada y ordenada (las palmeras con la orquídea) colocada en la esquina inferior izquierda, es una clara percepción de lo explicado. Que la ciudad este arriba de la selva en el anuncio no es casualidad, normalmente la condición de estar arriba de algo, es una connotación positiva en el pensamiento de la época, de igual manera es una forma de perpetuar la representación de que las ciudades, están en los EEUU mientras la selva, por estar abajo, está en Latinoamérica. Dicho sea de paso estos opuestos colocados en esas posiciones los vemos en propaganda de la UFCo desde 1945, mismos rascacielos, mismas palmeras.

Este punto es central, en el sentido que visualiza cómo el uso de una misma imagen insertada en un recurso gráfico, fue utilizada por la UFCo para construir y legitimar una representación geopolítica de la naturaleza latinoamericana en donde esta era transformada gracias a las ciudades del norte en hermosos jardines. Esos recursos, eran obtenidos de fotografías que se habían impreso en otros anuncios o en la revista UNIFRUITCO por ejemplo. ${ }^{55}$ Lo anterior sirve también para visualizar a estas fotografías como declaraciones visuales que en palabras de Barthes, se convierten en la construcción mental y material de los espacios. ${ }^{56}$

Nótese también que la ciudad está compuesta de "rascacielos", edificios que dentro del imaginario estadounidense de la época son una de las mejores expresiones de la iniciativa privada, el emprendedurismo y la conquista simbólica del cielo y la tierra. ${ }^{57}$ Por otro lado, el uso de las palmeras y las orquídeas para representar a América Latina es un recurso que evidentemente muestra una de las percepciones que se tenía para la naturaleza latinoamericana, para el caso en concreto lo que podría representar es una "selva" ordenada, en el tanto esa imagen es más común encontrarla en una costa o era parte de las ideas implantadas en la UFCo y su manera de perpetuar la transformación de la naturaleza en un bien de consumo, eso sí, en el marco de una cooperación mutua y que sirviera para marcar una diferencia entre palmeras y orquídeas versus ciudades con rascacielos.

Seguidamente el "intercambio" de materiales, hace constar la representación de que la naturaleza de Centroamérica y el Caribe (Middle America) solo produce los recursos agrícolas necesarios para los EEUU, no se hacen necesarios los bosques o la selva, esto se necesita para propiciar el beneficio mutuo, es una región con acres normälmente especializados en uno solo producto. El banano, el café, el cacao, las maderas, el azúcar y el abacá son los productos de las divisiones de la UFCo que nos indican nuestra especialización, es la manera de alcanzar el beneficio mutuo.

Por parte de la civilización, todos aquellos artefactos que indiquen la victoria de la modernidad sobre la selva son posicionados como los beneficios por obtener. Tractores que han comprobado su capacidad en las montañas58, refrigeradoras que permiten conservar alimentos, automóviles que en vez de caballos o bueyes, facilitan y hacen más

\footnotetext{
${ }^{54}$ Al igual que con los viajeros europeos a Costa Rica, como lo demostró Goebel., la ciudad era un referente a la civilización, sin embargo para el caso de la UFCo, las divisiones bananeras, aunque no tenía rascacielos, eran un aproximación al ideal de ciudad que se aspiraba desde la UFCo. Goebel, "Naturaleza Imaginada":182.

${ }^{55}$ Existe el caso muy concreto de la fotografía de la división Golfito utilizada en la revista UNIFRUITCO de 1949 con un anuncio publicado en el Barron's National Business and Finantial Weekly del 14 de Julio de 1958, la foto del Doctor Luis Sequiera aparece primero en un anuncios del departamento de relaciones publicas en el The Análisis Journal.vol12.no5 de Noviembre de 1956 y luego vuelve a aparecer en la UNIFUITCO de Mayo-Junio de 1957.

${ }^{56}$ Barthes. Cámara Lúcida.(España, paidos editorial, 2014).

${ }^{57}$ Juan Antonio Roche Cárcel "A la conquista de la tierra y del cielo Rascacielos y poder tecno-económico, Política y sociedad 44, 3 (2007): 89-129.

${ }^{58}$ Annual Report. United Fruit Company,1952
} 
cómoda la comunicación. ${ }^{59}$ Idea similar nos indican el teléfono que nos ayuda a que las distancias disminuyan y por último, los benéficos de la salubridad y la investigación para el progreso. Esa era la idea del círculo viviente, el intercambio de productos para unificar aún más las Américas, sin embargo esta publicidad generó cierta reticencia en algunos medios latinoamericanos pues la imagen del mapa representaba al imperialismo estadounidense. ${ }^{60}$ Aquí, la transformación exitosa de las zonas donde se encontraban las divisiones bananeras se representaba dándole una importancia bastante grande a los productos que podían salir de esos terrenos.

El círculo en palabras de Vitta significa, "...el ser cerrado en sí mismo y, por tanto, a la compleción, a la equidistancia de todos sus puntos respecto al centro, a la perfección; a la línea infinita, el tiempo sin fin, la eternidad siempre igual a sí misma..." ${ }^{61}$ De igual manera continua la representación de la Gran Flota Blanca. Esta fue la que desde el inicio de operaciones de la UFCo en la región se convirtió en una de las "imágenes marca" de la compañía, en el tanto de que representaba la ayuda por medio de los barcos de alcanzar los lugares más alejados y todos los aspectos que se generaban dada su condición de medio de transporte, no solo de los productos agrícolas, sino que también de personas, ideas y artefactos de la modernidad.

En síntesis, en la imagen se nos presentan maneras de contraponer la naturaleza y la ciudad, eso sí, ahora están los productos importantes con los nombres de los países, aspecto que ayudaba quitar las ideas anteriores de ver al continente como suplidor de recursos sin la participación de los países involucrados. Por otro lado, cuando en el material se afirma que"... we have a living circle of economics that strenghtens the Americas, bringing the people of the American republics closer and closer in bonds of friendship and better living". ${ }^{62}$ La naturaleza de las divisiones bananeras es visualizada como una caja chica única de donde obtener sus ganancias, esto siempre y cuando se consiguiera la transformación de medios biofísicos heterogéneos, en plantaciones donde la existencia de un solo producto se convertía en el ejemplo digno de mencionar a nivel latinoamericano. En el aspecto político, para 1956 la naturaleza y lo que se hacía con ella, se analizada más como una política hemisférica de hermandad pro democrática.

Si bien es cierto la idea del material es presentar al comercio como agente de desarrollo, el aspecto geopolítico intrínseco aquí, es el comercio de la transnacional entre las Américas. Estas representaciones de la naturaleza tendrán un tono diferente en el 'mismo anuncio pero para 1958. Aquí además de fomentar el beneficio mutuo, se invitaba a combatir la infiltración comunista. En ese sentido, la naturaleza y la forma en cómo se transformaba tomaba con el transcurrir del decenio de 1950 una posición más política ideológica que en los años anteriores.

Lo anterior pues con la política del buen vecino y sus representaciones, la naturaleza transformada era un lazo de unidad entre los países del hemisferio, después de 1958, pareciera que esa transformación evita la infiltración comunista.

Solo con visualizar el cambio de titulo, de ese mismo anuncio "This Free Way of Life Strengthes the Americas" (Esta es la manera libre de fortalecer las Américas), manifiesta un opuesto contrario a la manera libre de fortalecer las Américas.

\footnotetext{
${ }^{59}$ Con respecto al automóvil, en la edición de la revista Unifruitco de Julio-Agosto de 1955, se presenta un reportaje mostrando como el automóvil y las construcción de carreteras abrían los horizontes en Centroamerica. 6-7.

${ }^{60}$ McCann, Una empresa norteamericana. La tragedia de la United Fruit.

${ }^{61}$ Vitta, El sistema de las imágenes: Estética de las representaciones cotidianas, 312.

62 Base de datos Jstor. Barron's Businees and Finantial Weekly. (Enero, 13.1958): 64. Consultado el 23 de febrero del 2013.
} 
Aquí, el texto hace énfasis en marcar la importancia de que en el hemisferio occidental, ha surgido el nuevo concepto de la interdependencia entre las Américas, lo cual significaba por medio de las imágenes, una interdependencia de productos obtenidos de plantaciones y artículos modernos vendidos por los EEUU, todo lo anterior para lograr "... guards against communist inflitration". 63

Ahora la interdependencia, la transformación exitosa de la naturaleza en plantaciones de productos necesarios para los EEUU, eran la casa de los guardianes de la amenaza comunista y su manera de explotar los recursos naturales. La manera de representar la transformación de la naturaleza ya no significaba solamente unir a los dos Américas, ahora significaba combatir amenazas de otros sistemas económico-políticos, así, si en su momento el determinismo ambiental marco la "intervención" civilizatoria durante buena parte del siglo XIX y XX, la política del buen vecino y la Guerra Fría desde mediados del siglo XX legitimaron la transformación de la naturaleza.

\subsection{La conquista de la Selva en la División Golfito: Un símbolo del círculo viviente}

Como se mostró con anterioridad la representación de la naturaleza de la división Golfito durante el periodo de la política de la buena vecindad, permitió insertar el proceso de transformación de la naturaleza con ayuda de algunos refertes como los mapas y la Gran Flota Blanca. La representación geopolítica de la naturaleza en la División Golfito, fue consecuencia de algunas ideas que desde el determinismo geográfico se habían impuesto hacía la región latinoamericana. Sin embargo en el proceso histórico que continúa a los códigos geopolíticos del Destino Manifiesto y Doctrina Monroe, a saber el surgimiento de la Política de la buena vecindad, se puede constatar según lo explicado que algunas maneras de representar la naturaleza debieron de adecuarse a las nuevas necesidades y realidades. Así el uso del nombre del lugar en donde se encontraban las divisiones bananeras unido al producto exportado, fueron intentos de mejorar la visión que se tenía de la empresa de capital estadounidense.

El proceso de sintetizar códigos geopolíticos a representaciones de la naturaleza en las Divisiones bananeras fue configurado por medio de diferentes recursos para desarrollar ese proceso. Dentro de esa lógica la creación de documentos y materiales multimodales en castellano e inglés contribuyeron a la prolongación e implantación de las representaciones de la naturaleza que la UFCo necesitaba se convirtieran en conocimiento común.

Cuando en 1950 en el contexto de la Guerra Fría, la división Golfito y lo que sucedía ahí entró en ese juego político, tanto el "conocimiento útil" como el "círculo viviente" se integraron en un texto cuya portada (imagen 3) nos permite ver cómo esas representaciones se transportaron directamente para la población en la división Golfito. El formato de la publicación es similar a lo que ya nos había mostrado la compañía, un recurso gráfico en la parte superior y un recurso tipográfico jerarquizado abajo. Este documento en especifico se difundió por la división Golfito, pero contenía la mayoría de los aspectos y estructuras de las publicaciones propagandísticas de la UFCo, así desde los textos construidos por el Middle American Information Bureau, hasta las primeras señales de la Guerra Fría, ese documento se creó con el objetivo de brindar el conocimiento útil a los trabajadores bananeros de esa región. El texto fue publicado en el decenio de 1950 y recoge una serie de imágenes y de textos los cuales hablan de ese episodio descrito como; una novela real de los tiempos

${ }^{63}$ Base de datos Jstor. Barron's Businees and Finanantial Weekly. (Enero, 13.1958): 64. 
modernos64. En la División Golfito, su naturaleza transformada, refleja un ideal geopolítico que mira a la selva como la causa de la intervención y de la ayuda de la Compañía.

La imagen nos permite apreciar al tractor, símbolo de la modernidad, progreso y civilización, como instrumento que facilita la barrida de la selva. ${ }^{65}$ Como se puede apreciar el tractor está forjando un camino, aspecto que indicaba que se aceleraba el proceso de llevar la civilización a los lugares más alejados e inhóspitos del continente. El título, "Golfito: Una Historia de la conquista de la Selva", nos referencia que en Golfito, se está desarrollando un proceso civilizatorio importante, la referencia al lugar se prioriza, para después integrar lo que se está haciendo, que es "conquistar", concepto que denota esfuerzo, confortamiento o habilidad. De tal manera, la División Golfito pasó de ser un simple topónimo en un mapa de 1939, a un ejemplo que debía de ser conocido por la gente de su país y por los extranjeros. Se transformó en un ejemplo del círculo viviente.

La imagen del tractor manejado por un trabajador bananero botando la montaña, marca una pauta, pues se agrega dentro del proceso civilizatorio al trabajador de menor posición administrativa, pero gran colaborador desde la visión geopolítica de una naturaleza en transformación. En ese sentido es importante mencionar que el trabajador agrícola de las bananeras era considerado como el nuevo cowboy y para el caso concreto de la División Golfito, este vaquero se montaba a combatir la selva en el tractor, ser humano y maquina se unen para lograr el proceso civilizatorio. 66 Aquí la selva es representada también como la "frontera" en donde la iniciativa de la compañía pretende llevar la civilización a través del cultivo del banano y otros productos agrícolas necesarios para la época, con ayuda de personas "emprendedoras" y "trabajadoras" a decir de la empresa.

La conquista es llevada a cabo entonces en la frontera de Golfito, ya no es necesario el caballo ni expulsar a los "nativos", ahora la unión entre el ser humano y la maquina propician el beneficio del primero en detrimento de lo que se representa como el obstáculo a vencer, la selva, los pantanos, la naturaleza. El discurso está plagado de opuestos, selva / ciudad, naturaleza / jardín, selva/tractor, entre otros construyen la representación de que lo malo se asocia con lo salvaje y natural y lo bueno, lo necesario hacia el tractor, la ciudad, el jardín.

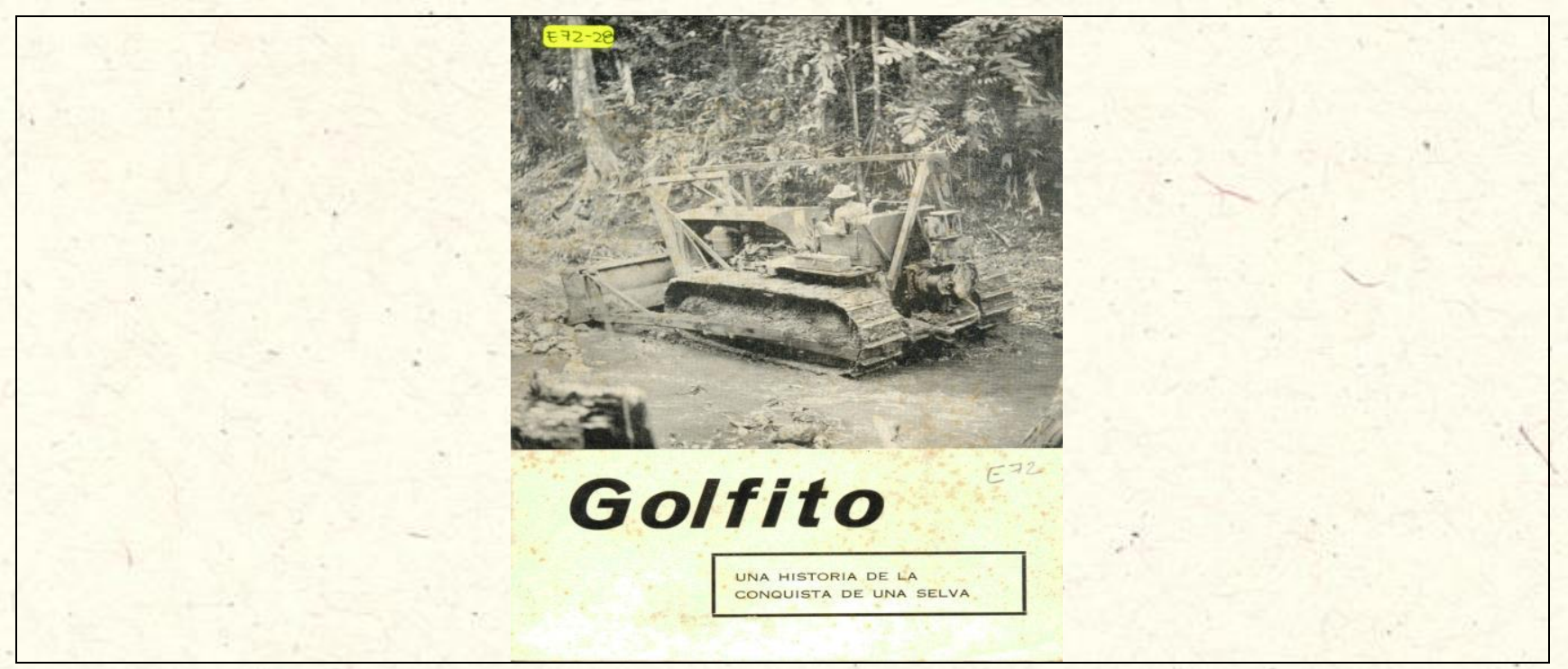

Imagen 4 - Golfito: Una Historia de la Conquista de la Selva.

Fuente: CIHAC. Colección Carlos Meléndez.

\footnotetext{
${ }^{64}$ Compañía Bananera de Costa Rica. Golfito: Una Historia de la Conquista de la selva.(1955).5.

${ }^{65}$ United Fruit Company. Annual Report for the year 1952. (1952): 5

${ }^{66}$ James W. Martin, "Becoming Banana Cowboys: White-Collar Masculinity, the United Fruit Company and Tropical Empire

in Early Twentieth-Century Latin America", Gender \& History (Agosto 2013):317-338.
} 
Continuando con las representaciones en la división Golfito, en el primer párrafo del texto mencionado se indica la importancia de este material, pues se afirma que:

\begin{abstract}
Ente los triunfos de la ingeniera moderna, ha de figurar la historia de Golfito. Es un bello ejemplo de la transformación de una selva impenetrable en un jardín agrícola de alta productividad. Afuera de Costa Rica esa historia es muy poco conocida, hay muchos detalles del drama que tampoco son de conocimiento nacional. En forma de tributo a los dedicados trabajadores costarricenses y extranjeros que hicieron posible la zona de Golfito tal como actualmente es, la Cía. Bananera de Costa Rica tiene mucho gusto en presentar un relato de esta novela real de tiempos modernos. ${ }^{67}$
\end{abstract}

El texto se convierte así, en la síntesis del proceso civilizatorio en Golfito y su historia, o al menos una parte de esta. La transición de una selva impenetrable a un "jardín agrícola de alta productividad", enfatiza el aspecto de que la naturaleza centroamericana, en este caso en concreto la de Golfito, debía ser transformada en la fuente de un producto agrícola o explotable alineado a un código geopolítico que vislumbraba nuestra naciones y su naturaleza como una fuente de materia prima o dentro de esa misma lógica, el objeto a intercambiar por maquinas, medicinas, "ciudades" - Progreso. La construcción y posterior representación de la naturaleza en la división Golfito a través de los códigos geopolíticos estadounidenses, convirtió la destrucción de un medio biofísico natural, a una plantación, ciudad jardín, en el prototipo de éxito latinoamericano.

Si bien es cierto, la transformación de la naturaleza en la división Golfito fue un ejemplo utilizado en los medios de comunicación masiva de la compañía desde el año de 1939, tanto en los reportes para socios como en la revista UNIFRUITCO, es innegable que a partir del decenio de 1950 la compañía se preocupó de crear materiales que pudieran ser leídos por los trabajadores de todos los niveles de las divisiones bananeras, propiciando la continuación de una serie de representaciones que se venían construyendo con ayuda de la política exterior estadounidense.

En ese sentido ideas como que:

el desarrollo de la región costera del Pacífico en Costa Rica continúa llevándose a cabo bajo el reciente contrato modificado que concede al gobierno de Costa Rica una participación del 30\% en las ganancias netas de las operaciones de la compañía bananera y de las operaciones de la Chiríqui Land Company [y que] ese programa de 12 años que convirtió la División de Golfito en región productiva y actual ensanche del valle de Coto demuestran el éxito de la colaboración inteligente para la explotación de los recursos naturales, entre una nación centroamericana y el capital estadounidense". 68

Ya fuera desde la política de la buena vecindad o en el contexto de la Guerra Fría, la construcción de plantaciones bananeras y ciudades jardín donde antes habían existido bandadas de pájaros marinos se debían de entender vislumbrando el mapa del continente Americano como un espacio de unidad, fraternidad e intercambio balanceado. En ese sentido es determinante la participación de los códigos geopolíticos desde los EEUU, las

\footnotetext{
${ }^{67}$ Compañía Bananera de Costa Rica. Golfito: Una Historia de la Conquista de la Selva: 3

${ }^{68}$ Compañía Bananera de Costa Rica. Golfito: Una Historia de la Conquista de la Selva, 15. el subrayado es nuestro.
} 
instituciones que se crearon para perpetuar ese código, la interpretación que realizó la UFCo de esos códigos y cómo lo insertó dentro de su lógica empresarial.

\section{Conclusiones}

Las representaciones geopolíticas de la naturaleza en la División Golfito durante este periodo de estudio evolucionaron a través de los códigos geopolíticos originados desde la política de la Buena Vecindad, así como los primeros años de la Guerra Fría.

Dentro de esa lógica y a la luz de la opinión del mismo presidente Roosevelt, la importancia de poner mapas como recursos gráficos los cuales facilitaran al público estadounidense là ubicación primeramente de los buenos vecinos y posteriormente de sus recursos, se convirtió en el primer factor del "conocimiento útil" para representar la naturaleza dentro de ese código geopolítico.

En un segundo lugar, el conocimiento útil además del uso del mapa debía indicar otras características, en ese aspecto la creación del Middle American Information Bureau (MAIB) por parte de la UFCo a partir de 1942, brindó una serie de documentos escritos y fílmicos, 69 los cuales permitieron conocer a los vecinos, ubicándolos y dando a conocer características generales de las ciudades capitales, propiedades de la compañía, etc.

En ese sentido el texto de "Place names in Middle America" ocupó un lugar de facilitador dentro de la lógica de la compañía en el entendimiento de las once repúblicas que integran esa región, desde el punto de vista geopolítico de la compañía. Este texto permitió una pequeña caracterización de algunos espacios dentro de los países donde se encontraban las divisiones bananeras, así las mismas divisiones, fincas experimentales entre otros lugares fueron presentados al público estadounidense como ejemplos del alcance hemisférico de la compañía.

De igual manera la participación de Edward Bernays y Charles Morrow Wilson en esta oficina es bastante importante, pues brindaron a través del seguimiento de sus trabajos anteriores, el origen y la forma en cómo era concebida la región centroamericana.

La legitimación de la ubicación de los buenos vecinos, responde a la construcción de códigos geopolíticos anteriores como el Destino Manifiesto y sobre todo a partir del entendimiento de que los países ubicados en el pacífico difícilmente se podrían utilizar como fuentes de materias primas de diferente índole. En ese sentido mucha de la propaganda utilizada en los diferentes medios de comunicación de la UFCo mencionó ese aspecto para legitimar la instalación e instauración de las relaciones hemisféricas más cordiales con los países latinoamericanos en general.

La naturaleza de las divisiones bananera desde esa lógica, debía de ser transformada en benéfico de las necesidades estadounidenses, pero la compañía desarrollo un discurso de beneficio mutuo para evitar asperezas en las regiones en donde se ubicaban las divisiones bananeras.

El periodo de estudio es caracterizado por la importancia que se le daba a la comunicación y los medios que facilitaban esta, así la Gran Flota Blanca se convirtió en la marca empresa de la UFCo, en el tanto su representación gráfica en la mayoría de los medios de difusión masiva como los diarios, la radio y la televisión ocupo el lugar privilegiado de representar a la compañía como un agente capaz de transportar la civilización a las regiones más alejadas del continente.

${ }^{69}$ United Fruit Company. Annual Report to the Stockholders of the United Fruit Company for the year 1948. Middle America. 
Esto es importante, pues como se mencionó en las primeras partes de este trabajo durante la "conquista" del Oeste estadounidense, el medio de transporte que marcó la llegada de la civilización fue el tren, dentro de la lógica discursiva de la UFCo y por sus características de empresa transnacional el barco y la figura de la Gran Flota Blanca ocupó el lugar del tren como medio de transporte adecuado y necesario para llevar la civilización a las regiones latinoamericanas y lograr así la conquista de la "selva".

La selva en general fue percibida también como "frontera", en el tanto una de las caracterizaciones utilizadas para referirse a los trabajadores agrícolas de la compañía era que se habían convertido en los nuevos Cowboys, pues ahora ya no en caballos, sino que en tractores se convertían a la par de la compañía en los facilitadores de ese proceso de transformación de la naturaleza y, por lo tanto, participes del beneficio mutuo hemisférico occidental.

Durante buena parte del período de estudio se pudo evidenciar la coherencia de representaciones geopolíticas de la naturaleza desde la UFCo, esto se constató a la hora de revisar fuentes como los reportes para socios, la revista UNIFRUITCO, documentos del Middle American Information Bureau y la propaganda del departamento de relaciones públicas de la compañía que aunque dirigidas hacia públicos diferentes las ideas los conceptos e inclusive las imágenes eran reutilizadas en función de construir una representación solidad, clara y coherente dentro de la lógica empresarial.

En ese sentido, el papel del departamento de relaciones públicas de la compañía a partir del decenio de 1950, tuvo un giro importante reflejado en el cambio de posición y de condición dentro de la lógica de la empresa (ver diagrama 3). Así a partir de 1955 con la proyección de la campaña "El circulo viviente", la compañía lanzó sus representaciones al público de habla española, que si bien es cierto desde 1945 la UNIFRUITCO era impresa y distribuida en inglés y español, los alcances de esta campaña se difundieron hasta en medios de comunicación masiva como la revista LIFE, tanto en inglés como en español.

La campaña del "círculo viviente" tomo como eje central la presentación de una parte del mapa del continente americano en donde se representaban los opuestos trabajados para explicar la idea de esta campaña, por un lado el intercambio comercial entre las materias primas agrícolas suministradas desde las divisiones bananeras en oposición a los artefactos tecnológicos y facilitadores de la civilización exportados por el país de origen de la compañía. En un segundo, la oposición entre las ciudades con rascacielos, las palmeras y orquídeas evidencian la visión representada de las divisiones bananeras como lugares en donde la naturaleza transformada, además de plantaciones eran también "jardines" para apreciar y visitar.

Esta campaña varió su discurso cuando entro en juego la amenaza comunista, la idea original del beneficio mutuo hemisférico, sufre un giro cuando ese benéfico se pudo ver perjudicado por la infiltración de agentes comunistas, aspecto que evidentemente se vivió muy fuerte en las divisiones bananeras.

En ese sentido, la figura de Edmund S. Whitman, director de ese departamento a partir de 1953, marco una tendencia conservadora y abiertamente anticomunista con fuertes lazos con la Casa Blanca en Washington, el mismo en su documento How an American company, through advertising and public relations, has combatted communism in Latin America,70 explica la manera en como la UFCo, logró vencer las amenazas

\footnotetext{
${ }^{70}$ Edmund Witman, How an American Company, through advertising and public relations, has combatted communism in Latin
} America UFCo. (New York, 1955). 
comunistas en la región como por ejemplo con la presentación de la película "Why the Kremlin Hastíes Bananas".

La historia de la división Golfito y las representaciones de la naturaleza que se hicieron de esta, queda inserta en toda esa lógica empresarial descrita para nuestro periodo de estudio:

A partir del año de 1939, cuando aparece en los reportes para socios, la división ocupa un lugar dentro de esa toma simbólica del espacio centroamericano. Ahora es parte del proyecto hemisférico y lo que suceda ahí es digno de mencionarlo a través de los distintos medios de comunicación. Cuando en 1949 la revista UNIFRUITCO dedica un reportaje acerca de la división, el uso de imágenes cargadas con referentes del progreso de la época como puertos y ciudades ordenadas, son legitimados y contextualizados por el uso de mapas para ubicar el lugar así como mencionar los logros alcanzados en esta división.

De igual manera cuando en el decenio de 1950, la Compañía Bananera de Costa Rica, subsidiaria de la UFCo, publica el texto "Golfito una historia de la conquista de la selva", el principal objetivo era desde nuestro punto de vista, brindarles a los trabajadores de la zona y a Costa Rica entera, un documento en donde quedara constancia la importancia de esta división bananera dentro de la lógica hemisférica. Por eso el uso de imágenes en la división, así como marcar el papel importante de los trabajadores agrícolas, el texto cumple también con las recomendaciones emitidas por los representantes de la embajada estadounidense cuando en el 27 de Octubre de 1955 visitaron la división.

Todo lo anterior deja constancia de que las representaciones sociales de la naturaleza deben ser estudiadas e interpretadas no solo como un conocimiento mutuo surgido del sentido común, también construcciones que desde otros espacios físicos o jurídicos, intentan legitimar y propiciar procesos económicos los cuales faciliten la especialización productiva de los países.

La relación entre el gobierno estadunidense y la UFCo, aunque tuvo sus asperezas, es innegable que fabricaron en comunión la representación geopolítica de la naturaleza en las divisiones bananeras, como el caso de Golfito, en función de sus intereses traducidos por sus códigos geopolíticos. 